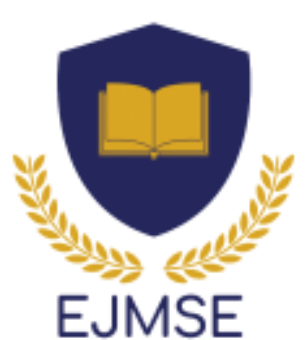

\section{European Journal of Mathematics and Science Education \\ Volume 1, Issue 2, 81 - 90.}

ISSN: 2694-2003

https://www.ejmse.com/

\title{
An Analysis of Errors and Misconceptions in the Study of Quadratic Equations
}

\author{
Jane Tendere \\ Great Zimbabwe University, ZIMBABWE
}

\author{
Lillias H. N. Mutambara*(iD) \\ Bindura University of Science Education, ZIMBABWE
}

Received: August 21, 2020 • Revised: November 6, $2020 \cdot$ Accepted: December 14, 2020

\begin{abstract}
This study attempts to investigate the errors and misconception that form three students reveal using symbolic equation and word-problem representations. The participants were thirty form three students, from a high school in Zimbabwe. Three mathematics teachers from the same school also took part. Data was collected from the students through a questionnaire, a test, follow up interviews and semi-structured interviews. Semi structured interviews were also conducted with the three mathematics teachers. In data analysis, the students' written responses and data from questionnaire were qualitatively analysed to determine the nature of the students' errors when solving quadratic equations. The results revealed that the students had difficulties in solving symbolic quadratic equations by the factorisation method as well as the use of the quadratic formula such that many misconceptions were exposed. The following types of errors were revealed: conceptual, procedural and technical. It was found out that it is an advantage for teachers to teach students with the knowledge of these errors in an effort to eliminate them.
\end{abstract}

Keywords: Error, misconception, quadratic equation.

To cite this article: Tendere, J., \& Mutambara, L. H. N. (2020). An analysis of errors and misconceptions in the study of quadratic equations. European Journal of Mathematics and Science Education, 1(2), 81-90. https://doi.org/10.12973/ejmse.1.2.81

\section{Introduction}

Solving quadratic equations is an important branch of Mathematics which cuts across all spheres. In Zimbabwe, learners are introduced to concepts of quadratic equations at form one level and the concepts are continuously developed at ordinary and advanced level. The application of the concept is enhanced at tertiary level. Ideally learners are expected to master this concept as they learn and apply it in real life situation. However, this is not the situation on the ground, as learners continuously make errors when solving quadratic equations at ordinary level hence fail to have a strong base for mathematics courses including calculus, differential equations and complex analysis at tertiary level. This is supported by (Vaiyavutjamai et al., 2005) who emphasise that for many secondary school students, solving quadratic equations is one of the most conceptually challenging subjects in the curriculum. Despite this, quadratic equations are considered important in school Mathematics curricula because they serve as a bridge between Mathematical topics such as linear equations, functions and polynomial as postulated by Saglam and Alacaci (2012). According to Alkan and Altun (1998) this has a direct bearing to the future of the learners. Learners who fail to comprehend basic concepts on solving quadratic equations will have problems in related areas like astronomy and the study of population growth. Learners will as well fail to pursue carriers in disciplines like Mathematics and Science which require application of such concepts. Didis and Erbas (2015) further argue that linear equations and quadratic equations are also applied in disciplines such as physics, engineering, and design, as they can be used in solving word problems, modelling and real-life situations. Such challenges and usefulness of the quadratic equations have prompted the researcher to carry out the study with the aim of exploring learners' level of understanding quadratic equations, consequently identifying the types of errors they make in order to bridge the gap between learning events and real-life situations.

\footnotetext{
* Corresponding author:

Lillias H. N. Mutambara, Bindura University of Science Education, Zimbabwe. $₫$ tendaimutambara@gmail.com
} 


\section{Literature Review}

Learners have serious problems in solving quadratic equations, (Makgakga, 2016, White, 2005; Luneta \& Makonye, 2010, Bossè \& Nandakumar, 2005, de Lima \& Tall, 2008). Kufakowadya and Nyamakura (2010) view a quadratic equation as an equation of the second degree. The standard form of a quadratic equations is given by $a x^{2}+b x+c=0$ where $\mathrm{a}, \mathrm{b}, \mathrm{c}$ are constants and $x$ is the unknown. However, Vaiyavutjamai and Clements (2006) were of the opinion that there is limited research on the teaching and learning of quadratic equations in mathematics education. Makhubele and Ayhari (2015) outlined that most students, have challenges in factorisation of quadratic equations and an inability to apply meaning to the quadratics. Nyaumwe and Buzuzi (2007) asserted that most students do not develop conceptual understanding of quadratic equations at ordinary level mainly due to the high rate of errors and misconceptions that they manifest.

Makonye (2014) sees an error as a mistake, slip and deviation from accuracy. The learners provide responses that are not in line with the expected answers. A misconception is seen as a misapplication of a rule, an over or under generalisation or alternative conception of the situation, (Hansen, 2006). In another study, Clark (2012) classifies errors into three types namely: operator, applicability and execution. An operator error is evident on learners who often reflect incorrect knowledge. For example, when factorising the equation $\left(x^{2}+2 x-4\right)=0$, the learner attempts the question by first factorizing as follows $(x+2)(x-4)=0$. This shows that this particular learner has not grasped completely the concept of factorizing a quadratic expression. Here, the learner has not included the middle term in the process of selecting factors. This scenario reflects an incomplete knowledge of quadratic equation factorisation.

An applicability error involves the misuse of the rules of algebra. For example, when expanding $6\left(2 a^{2}+1\right)=8 a^{2}+7$. In this example, the distributive law was applied incorrectly. Instead of multiplying the terms in the brackets by six, this learner seems to have added seven to the coefficient of ' $\mathrm{a}^{2}$ ' and a respectively. Execution errors include partial executions, such as; $3\left(4 x^{2}+1\right)=12 x^{2}+1$. In this example, the process of distributing the three over the brackets was done correctly on the first element which is $\mathrm{x}^{2}$ and nothing happened to one. This shows an incomplete task done. This reveals an execution error and on the other hand it sometimes results when learners copy the problems incorrectly. An applicability error involves the misuse of the rules of algebra.

Makgakga (2016) categorises the errors that learners make into two parts: conceptual and procedural whereas Kiat (2005) identifies three types of errors that occur when solving mathematical problems as conceptual, procedural as well as technical. The scholar argues that conceptual errors occur due to the lack of knowledge about mathematical facts and concepts, resulting due to failure to understand the relations involved in a problem. On the other hand, procedural errors occur when a student applies some procedures or attempt to implement a certain approach which is not appropriate to solve certain mathematical problems. According to Makgakga (2016), a student needs to have background knowledge about concepts to be covered, in order to acquire the procedural knowledge which enables use of relevant steps in solving mathematical problems by following the rules, methods and procedures in different representations.

Technical errors arise due to carelessness while carrying out an appropriate procedure. Misapplication of a previously learnt procedure is also seen as a technical error. Godden et al. (2013) also emphasise that these errors are a result of slips or silly mistakes that learners make. In this study, Kiat (2005) construct was adopted in order identify students' errors whilst solving systems of quadratic equations. In this view, Makonye and Nhlanhla (2014) commented that teachers need to be more sensitive to learners' errors and misconceptions in mathematics. The study is guided by the following research questions:

1. What types of errors and misconceptions do form three learners display in solving quadratic equations by factorization and the quadratic formula?

2. How could these errors and misconceptions be addressed?

\section{Methodology}

\section{Data collection tools}

In this study, the population covered all form three learners at a selected secondary school in Zimbabwe and all mathematics teachers at the school. A total of three mathematics teachers and ninety-six learners made up the population for this study. Cohen et al. (2011) view a sample as a smaller group or a subset of a population reflecting its characteristics. A sample of thirty learners and all the three mathematics teachers made up the sample for the study. Purposive sampling was used to select the teachers, and stratified sampling was used to select the learners. The researchers used a variety of instruments to collect data. A test and follow up interview were the instruments used to identify and classify errors made by learners in solving quadratic equation. The test was administered to the thirty learners selected from each group of fast, average and slow learners. In the test, learners had to show knowledge of some basic properties of quadratic equations. The test items were constructed using items in textbooks and past examination papers under the following three groups: solving equations (1) through the factorisation method (2) using 
the quadratic formula and (3) involving word problems. The test showed where errors occurred for instance; whether the learners could read the questions, comprehend the structure of the question, translate and solve it.

In order to ensure reliability of the test items, I ensured that the group to be tested was heterogeneous. I also made sure that the learners were given enough time to complete the test. Most of the questions were taken from past exam papers such that there were no poorly constructed questions. I also made sure that the test was long enough to cater for the content covered as well as the assessment domains. This method of assessment was also chosen so as to ensure the validity of the assessment procedures.

The researcher also used follow up interviews in order to allow learners to communicate their opinions and to express their actions which certify the insights in their thinking process. It is during such interviews when contradictions, insufficiencies or misconceptions can be noted from the students. Follow up questions were given to learners depending on the solutions obtained from the test. The main purpose of the follow up interview was to get insights into learners' constructions, interpretations and thinking processes, (Bertram \& Christiansen, 2014). Interview sessions with teachers and some students also served to gain more insights into why certain types of errors were committed by the students and to identify their learning gaps if they exist.

\section{Data Analysis}

The researcher used descriptive accounts to analyse the data. The researcher classified the categories of the errors made by the pupils. The coding and tally system was used to quantify the number of pupils with the same error and opinions. An in-depth content analysis was carried out. The participants' areas of difficulties were noted and errors and misconceptions were identified in order to answer research questions. Data analysis was also accompanied by images of the students' written work so as to generate rich data. The transcripts of the interviews were also analysed so that the findings could complement the written work. Students demonstrated errors namely conceptual, procedural and technical errors kiat (2005).

\section{Results}

\section{Students' responses to question one of the activity sheets}

An analysis of the first questions on solving quadratic equation by factorisation revealed that 19 students answered the question correctly. The other eleven students manifested conceptual, procedural and technical errors. Question 1 is displayed below.

Solve the equation $2 x^{2}+5 x+3=0$ using the factorisation method

\section{Conceptual error for question 1}

There were seven responses which showed conceptual errors of varying difficulties. These students treated $2 x^{2}, 5 x$ and 3 as if they were like terms hence adding them to get $10 x^{2}$. An example is displayed in figure 1 below.

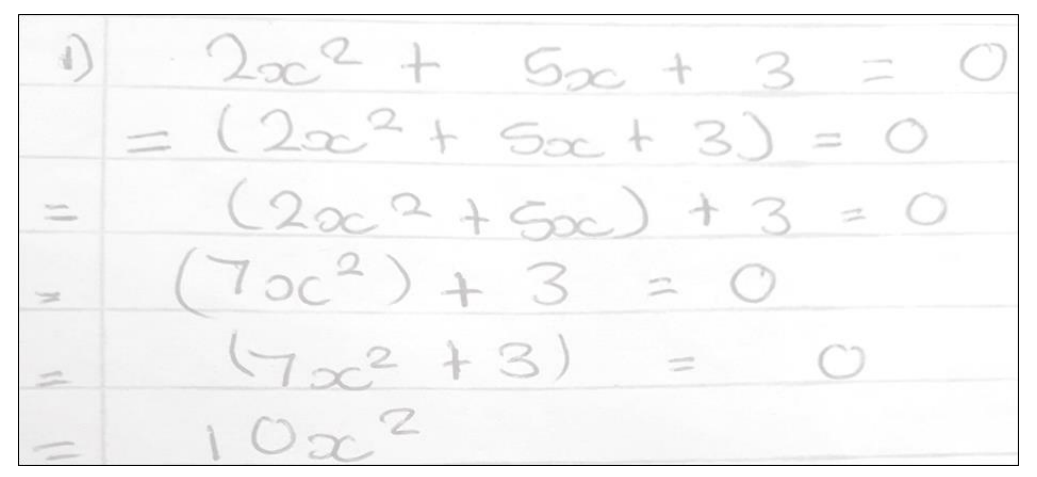

Figure 1: Student S3 response to question 1

The student's response showed that he did not even know how to solve this problem and was encountering some cognitive difficulties. The student did not even attempt to find the value of $x$. The following interview except took place with student S3

Researcher: Can you briefly explain how you have solved the equation above.

Students S3: Oh yes, I used the factorisation method.

Researcher: How did you factorise that expression 
Student S3: I introduced brackets first

Researcher: What did you do next

Student S3: I introduced brackets, collected like terms, and then add then together to get $7 x^{2}$.

However, I was stuck, because $7 x^{2}$ and 3 are not like terms.

The discussion with student S3 showed that firstly, he thought that the moment one introduces brackets, without taking anything out of them is carrying out factorisation. He had an idea about the concept of collecting like terms, but it is however interesting to note that the student is not aware that $2 x^{2}$ and $5 x$ are not like terms. The students however, was honest to say that he was stuck, so just consider $7 \mathrm{x}^{2}$ and 3 as like terms. The student's response revealed that he is experiencing cognitive challenges with the concept of solving equations. It shows that he or she does not know the essence of symbols and the equal sign was misplaced. All those students who experienced conceptual errors could not even attempt to find the value of $x$.

Two students exhibited procedural errors. They were able to factorise the expression correctly, but thereafter they got stuck. They did not know the next steps to follow. This was also revealed in the interview that was carried out with one of the students S5.

On the other hand, two students revealed technical errors. The two were able to carry out the correct factorisation, but obtained positive values of $x$ instead of the negative values $x$.

\section{Students' response to question two of the activity sheet}

An analysis of the second question on solving quadratic equations by factorisation revealed that 10 students answered the question correctly. The other 20 students manifested conceptual, procedural and technical errors. Question 1 is displayed below.

Solve the equation $5 x^{2}-3 x=2$ using the factorisation method.

The major problem was caused by the existence of the value 2 on the right-hand side of the equation instead of zero. The other mix up was the handling of the two negative terms $-3 x$ and -2 after rearranging the equation. However, the analysis revealed that 9 students exposed conceptual errors in their responses.

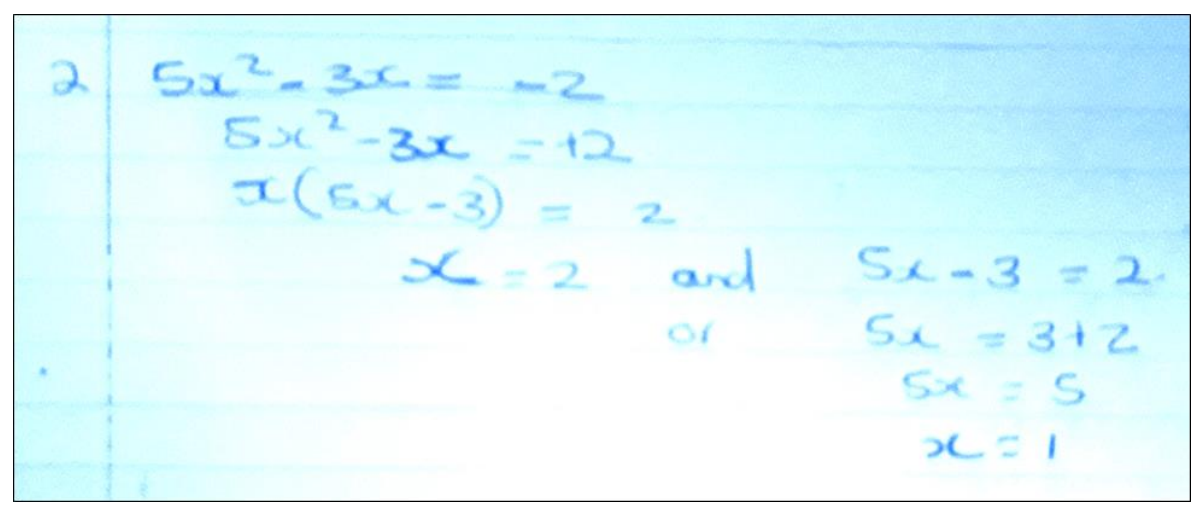

Figure 2. Written response of student $S 9$

Amongst the students who displayed conceptual errors, some failed to realise the fact that factorisation would only be done when one side remains with a 0 . As a result, they attempted to factorise the expression on the left-hand side leaving 2 on the right-hand side and then tried to solve the resultant equation as shown in figure 2.

The other 3 students understood the standard form of a quadratic equation since they were able to bring 2 to the lefthand side. However it is interesting to note that they again factorized the expression $5 x^{2}-3 x-2$ as, $x(5 x-3)-2=0$ neglecting -2 in the process and obtained the factors $(5 x-3)$ and $(x-2)$, thus manifesting technical error for failure to carry correct factorization. However, using their wrong factors they progressed to follow correct procedures to get the values of $\mathrm{x}$ as $\frac{3}{5}$ and 2 although the whole approach was incorrect.

Seven students revealed procedural errors. This category of students was able to bring 2 to the left-hand side, showing that they knew how to solve the equation. However, they obtained $-15 x^{2}$ as the product of $5 x^{2}$ and but then failed to find the factors which, when added, would give $-6 \mathrm{x}$. This shows that these students manifested technical errors and were 
being stuck in an attempt to factorise the expression. Another student $S 21$ was able to obtain the expression $5 x^{2}+2 x-5 x-$ 2 but introduced the brackets as follows $\left(5 x^{2}+2 x\right)-(5 x-2)=x(5 x+2)-1(5 x-2)$. The student ended up with the factors $(5 x+2),(x-1)$ and $(5 x-2)$ and resulting in three roots that is $-\frac{2}{5}, \frac{2}{5}$ and 1 . The following conversations took place with student $\mathrm{S} 21$, who also revealed a technical error.

Researcher: What type of equation is this one (pointing to question 2)?

Student S21: It is called a quadratic equation.

Researcher: What does that mean to say that a given equation is quadratic?

Student S21: Ummmm I am not sure. Is it that the highest power of $x$ is raised to the power 2?

Researcher: If you solve a quadratic equation, how many roots should you get?

Student S21: The value of $x$ I don't know, I got $-\frac{2}{5}, \frac{2}{5}$ and 1 .

The conversation with S21 shows she only memorized the algorithms without understanding the concepts. The student knows the steps to follow, but is caught up in an attempt to factorise it, by applying a wrong procedure in the way.

Students' response to question 3 of the activity sheet

An analysis of the third question on solving quadratic equation by using the quadratic formulae exposed that 10 students answered the question correctly. The remaining students manifested conceptual, procedural and technical errors. The students' performance in this question was not pleasing. Question 3 is displayed below

Solve the equation $3+6 x-5 x^{2}=0$ using the quadratic formula

\section{Conceptual error for question 3}

Seven students exposed conceptual errors in their work. Four students did not use the quadratic formula. They opted for the factorisation method which was not applicable according to the question. Two students used a wrong quadratic formula. One of the students wrote $x=\frac{-b \pm \sqrt{b^{2}-a-c}}{2 a}$ A follow up interview was done with student S4, who used the factorization method.

Researcher: May you read the question. (Teacher was pointing to question 3)

Student S4: Student read the question fluently.

Researcher: Looking at your response, do you think you did the correct thing?

Student S4: Ummm, no mem. The question required me to use the formula, but I could not recite the formula. I only remember that there is a square root sign.

Researcher: (The researcher wrote the quadratic formula on the piece of paper and asked the student to state the value of $a, b$ and $c$ )

Student: Oh yes that's the quadratic formula, I get it. The value of $a$ is $3, b$ is 6 and $c$ is -5 .

The researcher made a follow up on this question to check whether this student has misread the question. However, from the extract, it is evident that these students had cognitive difficulties with the use of the quadratic formula. The idea of the coefficients of $x^{2}$ and $x$ was not put into consideration, exposing some conceptual errors.

\section{Procedural Errors}

Six students failed to make meaningful substitutions in the formula $x=\frac{-b \pm \sqrt{b^{2}-4 a c}}{2 a}$, hence these students demonstrated procedural errors. These students were able to write down the correct quadratic formula but incorrectly assign the values of $a, b$ and $c$ whereas some of them ignored the negative signs when the numerical values of $a, b$ and $c$ were negative. Some attempted to write the equation starting with $5 \mathrm{x}^{2}$ but faltered on the way.

Seven of the students made meaningful substitutions only to falter on the manipulation of directed numbers. Lack of algebraic manipulation skills was exhibited as some students would hardly add, subtract or multiply terms with ease. This showed that these students demonstrated technical errors, since they are failing to apply already learnt concepts. 
Students' responses on question on quadratic equation story

The question was badly done though it was a straight forward question. Eight students got this question correct. The rest revealed conceptual, procedural as well as technical errors. Below is the question on quadratic equation story:

4. A rectangular playground measures $(x+2) m$ by $(2 x+1) m$. If the numerical value of the area of this playground is $30 \mathrm{~m}^{2}$, find the possible values of $\mathrm{x}$ correct to two decimal places.

\section{Conceptual errors}

The analysis showed that most of the students revealed conceptual errors. Ten students found it hard to comprehend the quadratic function story given. In other words, the students failed to convert from words to algebra, as a result they ended up formulating wrong quadratic equations.

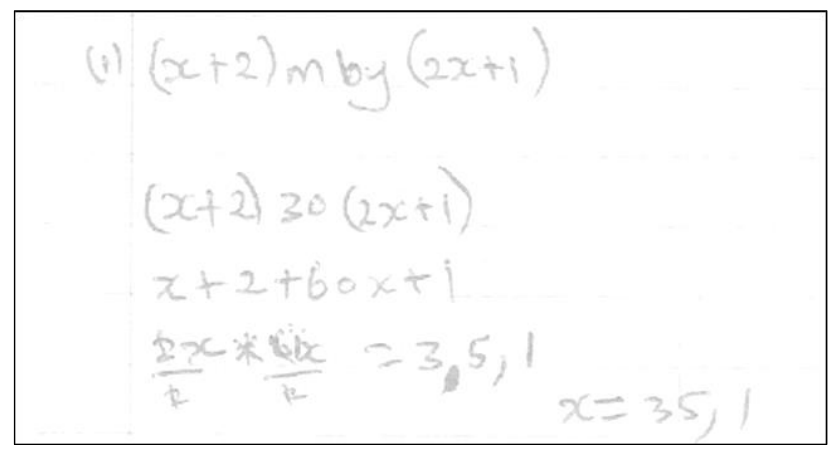

Figure 3: Student S25 written response

As if formulating the wrong quadratic equations was not enough, a number of the students went on to apply the quadratic formula wrongly as shown by student S25 above.

\section{Procedural errors}

The analysis of students' responses showed that three of the students were able to formulate the correct quadratic equations, that is $2 x^{2}+5 x+2=30$. However the students posted the constant 2 to the right-hand side, and then factorized the left-hand side. This becomes a procedural error because the equation is not in its standard form.

\section{Technical errors}

We noted that nine of the students revealed technical errors. The most technical errors that were evident here involved failure to manipulate figures, factorise the given expression as it involved negative numbers but were able to carry out correct procedures.

Data from the interviews

Table 1. Students' responses from the semi structured interviews concerning pre-requisite concepts.

\begin{tabular}{lcccccc}
\hline Do you have problems with the following? & Yes & $\mathbf{\%}$ & Sometimes & $\mathbf{\%}$ & No & \% \\
\hline Solving Linear Equations & 9 & 30 & 11 & 37 & 10 & 33 \\
Factorisation of quadratic equations & 14 & 47 & 8 & 26.5 & 8 & 26.5 \\
Algebraic Manipulations & 5 & 17 & 9 & 30 & 16 & 53 \\
Interpreting Mathematical stories & 19 & 63 & 6 & 20 & 5 & 17 \\
\hline
\end{tabular}

From the table, the highest number of students admitted that interpreting mathematical stories were a major problem to them with a combined $83 \%$ of them responding "yes" and "sometimes." Another hurdle pertains to the challenges with factorisation of quadratic equations as well as dealing with expressions dealing with directed numbers. Though some of them said they also have problems with manipulation of algebraic processes and simple linear equations but it was a small figure.

\section{The teacher and the challenges that students face.}

Learners were also asked to outline the role of their teacher in connection with the strategies used by the teacher during the learning process. The results are represented in the table below. 
Table 2. Student's responses concerning the role of a teacher

\begin{tabular}{|c|c|c|c|c|}
\hline Question & Yes & $\%$ & No & $\%$ \\
\hline Does he/she recap on important/basic concepts? & 18 & 60 & 12 & 40 \\
\hline Does he/she employ group work/pair work and frequent board demonstrations? & 17 & 57 & 13 & 43 \\
\hline Does he/she re-explain concepts for clarity? & 10 & 33 & 20 & 67 \\
\hline
\end{tabular}

Table 2 reveals that $60 \%$ of the students agreed to the view that recapping basic concepts before dealing with the concept at hand is vital for them to understand better that underlying concept. It also reveals that teachers try at times to employ strategies which help learners to understand some concepts well. However, the table further reveals that teachers do not take seriously the idea of re-explaining concepts for clarity. In their explanations, the students revealed that their teachers focus mostly on the high ability students with little attention being given to the low ability students. Thus, the low ability students continue to face the same problems since no one will be trying to rescue them.

\section{Teachers' interviews responses}

Researcher: Do you agree that students should master some basic skills before moving to new topics?

Teaches' responses: The three teachers (100\%) agreed that students should master some basic skills before moving to new topics. Pressed further to shed more light on the basic concepts required for a student to tackle quadratic equations well, the teachers pointed out that algebraic processes such as substitution, expansion and removal of brackets, directed numbers and the likes are the necessary concepts.

Researcher: With reference to the following sub-topics of quadratic equations: Factorisation method, quadratic formula and quadratic equation stories, what type of errors or misconceptions do most students commit?

Teachers' responses: In using the factorisation method to solve quadratic equations, one teacher (33\%) revealed that the concept of factorisation in itself is something which is not friendly to most students. He added that the students would make errors of factorisation particularly, "when negative terms are involved." The other teachers (67\%) revealed that students are not flexible enough to the extent that they may end up being deceived if the equation $a x^{2}+\mathrm{bx}+\mathrm{c}=0$ is given as $\mathrm{c}+\mathrm{bx}+\mathrm{ax}^{2}=0$. "In this case factorisation becomes a problem in itself to many students particularly if the values of $a, b$ and $c$ are negatives," one of the teachers lamented. In a way the teacher was admitting that directed numbers play a major role in solving quadratic equations.

Turning to the quadratic formula method, the three teachers $(100 \%)$ agreed that most students make errors due to the lack of substitution skills. This is so mainly when the values to be substituted are negatives. To add to this, the teachers also revealed that students may even fail to recall the correct quadratic formula since it is not given. At the end the students use a wrong formula thereby getting the wrong solutions. One teacher further claimed that the students may not be in a position to recognise the fact that there is need to use the quadratic formula on a given question. He explained: "Remember the question may not specify the method to be used so a student may just try to use the factorisation method thereby doing the wrong thing."

On the topic of quadratic equation stories, the teachers overwhelmingly supported the fact that students fail to comprehend the stories themselves. This leads them to wrong equations which, when solved, will automatically give the wrong results. "A few who would be lucky enough to comprehend the stories may not even finish the whole process successfully since they may still encounter some challenges in manipulating other algebraic processes," added one of the teachers.

Meanwhile, two of the teachers (67\%) supported the view that some teachers are also a source to the problems that the students face when dealing with mathematical concepts. They revealed that teachers sometimes fail to recap on important concepts, and they at times use their language inconsistently thereby creating some confusion to the learners.

Researcher: What then should the teachers do to help learners with problems of solving quadratic equations?

Teachers' responses: Learners should be given enough work for practice through preparing worksheets with typical examination questions. These worksheets should be accompanied by the relevant solutions so that the students will be in a position to check if what they have been doing is correct even if they would be working alone. There is need to always recap on vital concepts before tackling the quadratic equations. Fellow teachers ought to give students remedial work right at the spot so as to clear out any confusion before it would be too late. 


\section{Discussion}

An overview of the different kinds of responses for the four questions appears below.

Table 3. Summary of the number of different response types for the three questions

\begin{tabular}{lcccc}
\hline & Conceptual Errors & Procedural Errors & Technical Errors & Correct response \\
\hline Question 1 & 7 & 2 & 2 & 19 \\
Question 2 & 9 & 1 & 10 & 10 \\
Question 3 & 7 & 6 & 7 & 10 \\
Question 4 & 10 & 3 & 9 & 8 \\
\hline Total & 33 & 12 & 28 & 47 \\
\hline
\end{tabular}

Drawing from the analysis from table 3, it is evident that most of the errors encountered by learners in the learning of quadratic equations are conceptual and technical. Question 1 was a very simple with positive factors, which was not difficult to factorise. However the learnes struggled to solve it, for example student S3 written response showed that he did not even treat that expression as an equation, and could not even attempt to value of $\mathrm{x}$. The student was aware that that there was need to factorise to factorise the equation, but could not factorise it. This supports Stewart and Thomas (2010) contention that students simply know the straightforward procedural aspects of solving equations without having conceptual understanding of the concepts.

The learners also experience most of the technical errors due lack of prerequisite knowledge of basic concepts such as directed numbers, operation with negative numbers, substitution in a formular as well as simplifying given expression. For example students were able to write down the correct quadratic formular, but encountered lack of algebraic manipulation. This shows that a learner's existing schemas of a given mathematical concept significantly interferes with the construction of new knowledge, if it is not well mastered, Owusu (2015). This is also inline with Mbewe and Nkhata (2019)'s study who noted that learners difficulties in solving quadratic equations is a result of computational problems, problems with the negative sign as well as the square root. In question 4, it is also evident that the learners failed to convert words to algebraic expression, thus demonstrating conceptual errors. Student S25 could not come up with the correct equation. She failed to equate the product to 30, revealing a conceptual error. Kazunga and Bansilal (2017) noted that many students are not able to engage with various concepts because of limited conception about the demands of the question. She wrote $(x+2) 30(2 x+1)=x+2+60 x+1$. This also shows that the students is aware of the procedures to follow, but lack prerequisite concepts, could not expand the bracket correctly, hence obtaining $60 x+1$ which is a technical error. I also noted that, in the interviews at first the learners where first trapped to their errors. However after some probing and some hints, the learners were able to correct their misconceptions and errors. It is important to note that this study attempted to look at both the use of factorisation method, the quadratic formular as well as assessing students difficulties when solving number stories. Ojose (2015) further suggests that misconceptions that persist for years if not visible and identified would negatively affect the effective learning of mathematics.

\section{Conclusion}

From the discussion above, it can be seen that the type of student error in using the factorisation method is mainly procedural whereby they fail to execute the necessary working steps in order to find the answer, due to the lack of prerequisite knowledge of basic concepts and skills such as directed numbers.

The type of student error in using the quadratic formula is mainly conceptual whereby the students fail to apply the formula meaningfully, and technical due to the lack of pre-requisite knowledge of basic skills and concepts such as substitution and the operation of negative terms. When solving quadratic stories, students mainly have conceptual and technical errors whereby the students fail to convert words to algebra, due to the lack of understanding of what the given stories ask them to do. We also noted that teachers should recap on vital concepts and skills, and should not concentrate on the high ability students with little or no attention given to the low ability students. Thus, these teachers need to be more sensitive about learners' errors and misconceptions in mathematics. It is important to treat learners' errors in solving mathematical problems seriously. They should also ensure that the students have a clear understanding of basic concepts and skills learned in the early stages. The teachers should also develop consistency in the teaching methods, use mathematical language with great care, and above all, attend in-service courses or mathematical association workshops so that they will be confident in teaching mathematical concepts. It is important for teachers to understand students' errors in order to plan their lessons with these errors in mind (Brodie, 2014; Makgakga et al., 2011).

\section{Recommendation}

In line with the conclusions drawn concerning the problems that the form three students face, it is recommended that teachers treat learner errors in solving mathematical problems. They also need to recap the vital concepts and skills before teaching quadratic equations such as directed numbers, factorisation, expansion of brackets as well substitution. 
The educators must concentrate on one point at a time and proceed stepwise in a logical manner so as to encourage critical reasoning.

\section{Recommendations for further studies}

However, this study recommends that further research can be done to make use of the students' misconceptions and errors identified and make an assessment with the prior teaching. Further research can also look at how learner errors and misconceptions in algebra develop.

\section{Limitations}

The research instruments used have their own disadvantages which in turn might have an effect on the findings of the study. The researchers however used a variety of instruments.

\section{References}

Alkan, H., \& Altan, M. (1998). Matematik öğretimi [Mathematics teaching]. Anadolu Üniversitesi Açık Öğretim Fakültesi/ Anadolu University Open Education Faculty.

Bertram, C., \& Christiansen, I. (2014). Understanding research: An introduction to reading research. Van Schaik Publishers.

Bosse, M. J., \& Nandakumar, N. R. (2005). The factorability of quadratics: Motivation for more techniques (Section A). Teaching Mathematics and Its Applications, 24(4), 143-153.

Brodie, K. (2014). Learning about learner errors in professional learning communities. Educational Studies in Mathematics, 85(2), 221-239.

Clark, M, K. (2012). History of mathematics: Illuminating understanding of school mathematics concepts for prospective mathematics teachers. Educational studies in Mathematics, 81, 67-84.

Cohen, L., Manion, L, \& Morrison, L. (2011). Surveys, longitudinal, cross sectional and trend studies. Routledge.

de Lima, R. N., \& Tall, D. (2008). Procedural embodiment and quadratic equations. Educational Studies in Mathematics, $67,3-18$.

Didis, M.G., \& Erbas, A.K. (2015). Performance and difficulties of students in formulating and solving quadratic equation with one unknown. Educational Science, Theory and Practice, 15(4), 1137-1150.

Godden, H., Mbekwa, M., \& Julie, C. (2013). An analysis of errors and misconceptions in the 2010 grade 12 mathematics examination: A focus on quadratic equations and inequalities. In Z. Davis \& S. Jaffer (Eds.), Proceedings of the 19th Annual Congress of the Association for Mathematics Education of South Africa (pp. 70-79). Association for Mathematics Education of South Africa.

Hansen, A. (Ed.). (2006). Children's errors in mathematics. Learning Matters Ltd.

Kazunga, C., \& Bansilal, S. (2017). Zimbabwean in-service mathematics teachers' understanding of matrix operations. The Journal of Mathematical Behavior, 47, 81-95.

Kiat, S. E. (2005). Analysis of students' difficulties in solving integration problems. The Mathematics Educator, 9(1), 3959.

Kufakowadya, M. B., \& Nyamakura, A. (2010). Mathematics today. Zimbabwe Publishing House.

Luneta , K., \& Makonye, P.J. (2010). Learner errors and misconceptions in elementary analysis: A case study of a grade 12 class in South Africa. Acta Didactica Napocensia, 3(3), 35-46.

Makgakga, S. (2016). Errors and miscanceptions in solving quadratic equations by completing a square. Association for Mathematics Education of South Africa. http://shorturl.at/hzALU

Mbewe, T. L., \& Nkhata, B. (2019). secondary teachers' mathematics knowledge for teaching quadratic equations: A case of selected secondary schools in Katete district. Zambia Journal of Teacher Professional Growth, 5(1), 38 - 55.

Nyaumwe, L., \& Buzuzi G. (2007). Teachers attitudes towards proof of mathematical results in the secondary school curriculum. Mathematics Educational Research Journal, 19(3), 21-32.

Makonye, J. P. (2014). Learner mathematical errors in introductory differential calculus tasks: A study of misconceptions in the senior certificate examinations [Unpublished doctoral dissertation]. University of Johannesburg.

Makonye, J. P. (2012). Learner errors on calculus tasks in the NSC examinations: Towards an analytical protocol for learner perturbable concepts in introductory differentiation. International Journal of Learning, 18(6), 339-357. 
Makonye, J., \& Nhlanhla, S. (2014). Exploring 'non-science' grade 11 learners' errors in solving quadratic equations. Mediterranean Journal of Social Sciences, 5(27) 634-644. https://doi.org/10.5901/mjss.2014.v5n27p634

Makonye, J. P. (2012). Learner errors on calculus tasks in the NSC examinations: Towards an analytical protocol for learner perturbable concepts in introductory differentiation. International Journal of Learning, 18(6), 339-357.

Ojose, B. (2015). Misconceptions in mathematics: Strategies to correct them. University Press of America.

Owusu, J. (2015). The impact of constructivist-based teaching method on secondary school learners' errors in algebra [Unpublished Doctoral dissertation]. University of South Africa.

Saglam, R., \& Alacaci, C. (2012). A comparative analysis of quadratics unit in Singaporean, Turkish and IMDP mathematics textbooks. Turkish Journal of Computer and Mathematics Education, 3(3), 131-147.

Vaiyavutjamai, P., Ellerton, N. F., \& Clements, M. A. (2005). Students' attempts to solve two elementary quadratic equations: A study in three nations. In P. C. Clarkson (Ed.), Proceeding of Building connections research, theory and practice: MERGA 28 (pp. 735-742). Mathematics Education Research Group of Australasia.

White, A. L. (2005). Active mathematics in classrooms: Finding out why children mistakes - And then doing something. Square One, 15(4), 15-19. 